Article

\title{
Lipidic Matrixes Containing Lemon Essential Oil Increases Storage Stability: Rheological, Thermal, and Microstructural Studies
}

\author{
John Rojas *, Sergio Cabrera, Gelmy Ciro and Ana Naranjo \\ College of Pharmaceutical and Food Sciences, University of Antioquia, University campus, Calle 67 No. 53-108, \\ Medellín 050010, Colombia; sergiocabrera@gmail.com (S.C.); gelmy.ciro@udea.edu.co (G.C.); \\ ananaranjo@gmail.com (A.N.) \\ * Correspondence: jhon.rojas@udea.edu.co; Tel.: +57-4-2195472; Fax: +57-4-2195460
}

Received: 8 May 2020; Accepted: 27 May 2020; Published: 5 June 2020

\begin{abstract}
Lemon essential oil (LEO) is known for having excellent antioxidant properties with applications in the pharmaceutical, food and cosmetic sectors. However, its deficient stability to light and temperature compromise this activity. In this study, waxy emulsifiers, such as beewax, candelilla wax, carnauba wax, and ozokerite wax, were employed in order to create lipidic matrixes with LEO as a continuous phase by heating to $80^{\circ} \mathrm{C}$ under homogenization, followed by rapid cooling to $25^{\circ} \mathrm{C}$. The thermal, microstructural, rheological, and antioxidant tests were then conducted on such matrixes. The difference in melting, crystallization, and gelling temperatures was explained by the diverse chemical composition (long-chain wax esters in carnauba wax having a high melting point, and short-chain fatty acids and hydrocarbons in beewax and ozokerite wax, respectively). Crystal habits of these matrix systems varied from grainy, oval, to fiber-like shape, whereas there was a prevalent orthorhombic allomorph. The alignment and reorganization of carnauba and candelilla wax crystals led to an increase in the matrix strength as compared to those of beeswax and ozokerite matrixes, which showed a weak texture and poor crystallization behavior. The last two matrix systems showed the best flow and extensibility. These lipidic matrixes showed potential use for topical applications having good oil retention capacity and better antioxidant properties as compared to the raw essential oil.
\end{abstract}

Keywords: antioxidant properties; citrus lemon oil; extensibility; flowability; lipidic matrixes

\section{Introduction}

Essential oils (EOs) are natural, oily, colorless, and volatile liquids soluble in alcohol, ether, and vegetable oils, but insoluble in water. These are found in oil glands present at different depths in the flowers, buds, herbs, fruits, seeds, leaves, twigs, bark, and roots. These oils are commonly used in perfumery, toiletries, and personal hygiene products. EOs extraction is usually conducted by steam or hydro-distillation, cold pressing, organic solvent, and supercritical $\mathrm{CO}_{2}$ extraction from specific plant organs [1]. The extraction method along with the soil type, provenance, genotype, climate, age, organ, and plant vegetative stage affects the quality and quantity of their components [2]. EOs are composed by complex mixtures of lipophilic compounds at different concentrations in which two or three major components prevail at high concentrations as compared to trace amounts of others compounds. Usually, those main compounds are responsible for the attributed biological properties [3]. Most of the commercial EOs are mainly chemotyped by gas chromatography (GC) and mass spectrometry (MS) analyses. These instrumental analytical techniques allow for a precise characterization of the volatile fraction. Other techniques, such as liquid chromatography, Raman, and Fourier-Transformed Infrared Spectroscopy 
(FT-IR) are extensively used for the assessment of authenticity, impurities, geographical origin, and possible adulteration $[4,5]$. EOs are an important ingredient in packaging, food, and pharmaceutical industries, since they exhibit biological activities, such as antimicrobial, analgesic, sedative, and anti-inflammatory properties. They can also penetrate the skin and unfold local effects, such as skin hydration and skin elasticity, possibly due to accumulation in the fatty tissue after dermal application [6].

Citrus oils are of especial interest, since they represent one of the largest EOs production worldwide. The most commercialized citrus species are sweet oranges, tangerines, lemons, limes, and grapefruits in decreasing order. The oil content of citrus peels range between 0.5 and $5.0 \%(\mathrm{w} / \mathrm{v})$ and it is composed by a mixture of monoterpene and sesquiterpene hydrocarbons and their oxygenated derivatives. The main component of citrus oils is limonene ranging from 68 to $98 \%$ in sweet orange, from 45 to $76 \%$ in lemon and from 32 to $45 \%$ in bergamot [7]. Citrus oils possess antioxidant and hydrating activities that could prevent the damaging effect of air pollutants, and UV radiation, such as phototoxicity, skin aging, inflammation, and melanoma [8]. Therefore, they could also replace synthetic antioxidants, such as benzoates, nitrites, butylhydroxyanisole, and butylhydroxytoluene, which have shown harmful effects on human health [9]. Particularly, the Citrus limon (L.) essential oil (LEO) has been used in topical preparations to nourish, exfoliate, reduce itching, and treat pimples and wrinkles. These biological activities are attributed to the composition of non-polar isoprenoids, such as limonene (54.6\%), $\gamma$-terpinene (19.1\%), $\beta$-pinene (14.5\%), $\alpha$-pynene $(3.9 \%)$, geranial $(2.3 \%)$, and myrcene (1.5\%) [10]. The exact composition depends on the climate, cultivation conditions, variety and cultivar, extraction, and separation techniques. This oil is also considered as safe due to their non-toxic nature and hypoallergenicity. However, the compounds of this oil are highly volatile, water insoluble, and instable to heat, oxygen, and light, resulting in being challenging for the development of topical preparations [11]. Therefore, several strategies involving microparticulate systems have been developed to formulate oily bioactive substances (OBS) utilizing polymeric and lipidic materials. The former involves techniques, such as solvent evaporation, emulsion polymerization, and inclusion polymers utilizing toxic solvents that yield impurities in the resulting product [12]. On the other hand, lipidic vesicles, such as liposomes, ethosomes, and O/W emulsions, containing waxy compounds pose an innate instability, since, in aqueous media, phospholipids and triglycerides can slowly become oxidized or hydrolyzed [13].

One of the probable solutions to this problem is the entrapment of the OBS into a colloidal lipidic matrix (LM) due to the solid-like state of these systems, reducing the oil mobility and its leakage [14]. If this LM does not melt at body temperature, the OBS are released in a controlled fashion by matrix degradation rather than diffusion. The LM protects the oil from degradation by skin enzymes and, thus, serves as a localized OBS delivery in some types of skin ailments [15]. Hot homogenization is the most widely used preparation method for these matrixes, due to the good reproducibility, high concentration of lipid phase, and absence of organic solvents. This method implies heating above the lipid melting point under homogenization or ultrasonication, followed by rapid cooling in order to achieve partial crystallization [16]. The LM enhances skin penetration, hydration, and film forming properties as compared to current emulsions. As a result, an occlusive effect takes place, which in turn is proportional to the degree of crystallinity of the matrix, whereas amorphous materials do not have occlusive properties. Thus, a high crystallinity and, hence, occlusive effect prevents OBS from evaporation allowing for a deeper penetration into the skin [17]. Further, highly crystalline LM might act as physical sunscreens scattering or reflecting UV radiation. LM are able to retain OBS without the need of additives due to the formation of intramolecular (H-bonding and polar-polar interactions) and intermolecular interactions (dipole-dipole interactions) between the constituents stabilizing the structure of the crystalline network [18]. Therefore, the polarity of OBS affects the magnitude of crystal formation and self-assembling, since compounds having low polarities assemble into short and dispersed fibers that grow and become interconnected, whereas highly polar compounds form conglomerates due to the free mobility in the medium. Thus, an apparent balance between hydrogen bonds and hydrophobic interactions is critical easing self-assembling and the development of a defined 
micro architecture. In fact, the waxy molecules should be partially insoluble with the OBS to encourage crystallization, but, at the same time, should be partially miscible within the OBS to generate polar and hydrogen bond interactions [19].

The incorporation of complex lipids, such as natural waxes into LM, enhances crystal formation and loading capacity as compared to pure triglycerides. These waxes are able to form an isotropic LM with oils, cosolvents, and surfactants due to the low polarity, long chain length, and high melting point of their compounds (Table 1) [20]. They are very stable resisting oxidation and hydrolysis, and contribute to the excellent skin tolerance, lubrication, and cleansing performance of LM [21].

Table 1. Chemical composition of waxy emulsifiers.

\begin{tabular}{|c|c|c|c|c|c|c|c|}
\hline $\begin{array}{c}\text { Waxy } \\
\text { Emulsifier }\end{array}$ & $\begin{array}{l}\text { Aliphatic } \\
\text { Ester (\%) }\end{array}$ & $\begin{array}{l}\text { Hydroxy } \\
\text { Esters (\%) }\end{array}$ & Diesters (\%) & $\begin{array}{l}\text { Hydrocarbon } \\
\qquad(\%)\end{array}$ & $\begin{array}{c}\text { Free Fatty Acids } \\
(\%)\end{array}$ & $\begin{array}{c}\text { Fatty } \\
\text { Alcohol } \\
(\%)\end{array}$ & Ref. \\
\hline Beewax & $C_{40-0}: 35$ & $C_{24-34}: 12$ & $C_{54-68: 17}$ & $C_{21-35}: 14$ & $\mathrm{C}_{16}, \mathrm{C}_{24}, \mathrm{C}_{34}: 14$ & $C_{24-36}: 1$ & {$[22,23]$} \\
\hline Carnauba & $C_{50}: 38-40$ & 13 & 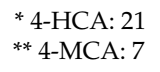 & $C_{27-28}: 1$ & $C_{16}: 5$ & $C_{32-34}: 12$ & {$[24,25]$} \\
\hline Candelilla & $\begin{array}{l}\text { Simple } \\
\text { esters-lactones: } \\
\quad 21\end{array}$ & $6-8$ & 0 & $\begin{array}{c}\text { nonacosane: } \\
2.5 \\
\text { hentriacontane: } \\
46-46.5 \\
\text { triacontane: } \\
2.5\end{array}$ & 5 & $12-14$ & {$[26,27]$} \\
\hline Ozokerite & 0 & 0 & 0 & $\begin{array}{c}\text { cerecin: } 40-60 \\
\text { mineral oil: } \\
25-45 \\
\text { petroleum } \\
\text { resins: } 12 \\
\text { asphaltens: } \\
1-3 \\
\text { parafin: } 1\end{array}$ & 0 & 0 & [28] \\
\hline
\end{tabular}

The aim of this study was to evaluate the rheological, thermal, and microstructural properties of lipidic matrixes produced with representative natural waxes and LEO. The topical application of these lipidic matrixes allows for a localized action, reduce the systemic risk of toxic effects, avoid first-pass hepatic metabolism, it is painless, easy, and increase patient compliance.

\section{Materials and Methods}

\subsection{Materials}

Steam-distilled Lemon essential oil was purchased from Green Andina (Bogota, Columbia). Natural waxes were obtained from L\&F (Medellín, Columbia). Absolute ethanol (lot SHBK8928), sodium carbonate (Lot 94F-0313), sodium acetate trihydrate (Lot SLBX1773), 2,4,6-tri-(2-pyridyl)-1,3,5-triazine (lot BCBW9015), 2,2-diphenyl-1-picrylhydrazil (lot BCBQ6979), nitroblue tetrazolium (NBT) (lot BCBQ6979), and nicotinamide adenine dinucleotide (NAD) (lot BCBQ6979), were obtained from Sigma-Aldrich (St. Louis, MO, USA). Ferric chloride. $6 \mathrm{H}_{2} \mathrm{O}$ (lot 176057) and dimethyl sulfoxide (lot 183521) were purchased from Fisher Chemical (Sunnyvale, CA, USA). In addition, ( \pm )-6-hydroxy-2,5,7,8-tetramethylchromane-2-carboxylic acid (Trolox $\left.{ }^{\circledR}\right)(97 \%$, lot A0405014) and gallic acid (A0267865) were acquired from Acros Organics (Morris Plains, NJ, USA). Further, 3-(4,5-dimethylthiazol-2-yl)-2,5-diphenyl-tetrazolium bromide (MTT) (lot p31b064) was purchased from Alfa Aesar (Haverhill, MA, USA). Methanol (lot 1823009611), Folin-Ciocalteu phenol reagent (lot hc43368401), and tetrahydrofuran (lot dg643), were obtained from Merck (Darmstadt, Germany). 2,2'-Azino-bis(3-ethylbenzothiazoline-6-sulfonic acid), 2, 2-diphenyl-1-picrylhydrazil (067k lot 1154), and diammonium salt (lot slbp9592v) were obtained from Sigma-Aldrich (St. Louis, MO, USA). 


\subsection{Preparation of Lipidic Matrixes}

Approximately, a $15 \%$ wt wax dispersion was prepared by adding $45 \mathrm{mg}$ of wax to a LEO ( 3 $\mathrm{mL})$ solution. The samples were then heated at $80{ }^{\circ} \mathrm{C}$ under mild agitation (200 rpm) while using a heating plate coupled with a magnetic stirrer (Gehaka, MS7-H550-S, São Paulo, Brazil) until clear solutions were obtained ( $5 \mathrm{~min}$.). These colloidal dispersions were then allowed to cool down to $25^{\circ} \mathrm{C}$ in a water bath within two minutes before testing.

\subsection{Thermal Behavior}

The thermal profiles of these matrix systems were examined with a DSC (200PC, Nietzsche, Feinmahltechnik $\mathrm{GmbH}$, Selb, Germany) equipped with a refrigerated cooling system. Nitrogen was used as purge gas. The cell constant and temperature were set with indium. The sample (weighing from 9-12 $\mathrm{mg} / \mathrm{cup}$ ) was placed inside an aluminum pan and sealed with an aluminum lid. The samples were equilibrated at $5{ }^{\circ} \mathrm{C}$ and then heated to $80^{\circ} \mathrm{C}$ (heating step) at a rate of $10^{\circ} \mathrm{C} / \mathrm{min}$., followed by a cooling step to $5^{\circ} \mathrm{C}$ at a rate of $10^{\circ} \mathrm{C} / \mathrm{min}$. Characteristic parameters of the thermal curves, including onset temperature $\left(\mathrm{Tc}_{\mathrm{onset}}\right.$ and $\left.\mathrm{Tm}_{\mathrm{onset}}\right)$, peak maximum temperature ( $\mathrm{Tc}$ and $\mathrm{Tm}$ ), offset temperature $\left(\mathrm{Tc}_{\text {offset }}\right.$ and $\left.\mathrm{Tm}_{\text {offset }}\right)$, melting and crystallization enthalpies $(\Delta \mathrm{Hm}$ and $\Delta \mathrm{Hc})$, and $\Delta \mathrm{T}\left(\mathrm{Tc}_{\text {onset }}-\mathrm{Tm}_{\text {offset }}\right)$ were obtained while using the Nietzsche Analysis software.

\subsection{Phase Contrast Microscopy}

The microstructure of these matrix systems was observed using an inverted phase contrast microscope (IN300, Amscope, Germany) that was equipped with a color camera CCD-MT (Amscope Vs. 3.7, Corp, CA, USA) at a 400× magnification. Fluorescence images were taken with a fluorescent mercury lamp with a double emission light from 460-490 nm and from 550 to $5150 \mathrm{~nm}$.

\subsection{X-ray Diffraction}

Polymorphism was investigated on a PANalytical diffractometer (Empyrean 2012, Westborough, MA, USA) operated at $40 \mathrm{kV}$, and $30 \mathrm{~mA}$, equipped with a monochromatic $\mathrm{Cu} \mathrm{K} \alpha 1=1.5460 \mathrm{~A}^{\circ}$, $\alpha 2=1.54438 \mathrm{~A}^{\circ} \mathrm{X}$-ray diffraction. Diffractograms were obtained over a $5-35^{\circ} 2 \Theta$ range and step scan and step time of 0.039 and $32 \mathrm{~s}$, respectively. The degree of crystallinity was calculated while using the Peak fit software (Seasolve ${ }^{\circledR}$, Inc Framingham, MA, USA) by separating the crystalline and amorphous scattering radiation using the baseline selection tool.

\subsection{Rheological Behavior}

Rheological measurements were carried out using an advanced rheometer (MCR92, Anton Paar, Graz, Austria) that was equipped with a Peltier system for temperature control. A parallel plate (cross-hatched; diameter, $\phi=25.0 \mathrm{~mm}$; gap $=400 \mu \mathrm{m}$ ) geometry was used to determine the linear visco-elastic region.

\subsubsection{Isothermal Measurements (Strain and Frequency Sweeps)}

Strain sweeps at a constant frequency of $1 \mathrm{~Hz}$ were performed to determine the linear viscoelastic region (LVR). The strain ramp was conducted between 0.01 to $100 \%$, at $1 \mathrm{~Pa}$, and $25^{\circ} \mathrm{C}$. The time-dependent deformation behavior of these matrix systems was conducted at angular frequency $(w)$, ranging from 0.1 to $100 \mathrm{rads}^{-1}$ and $1 \mathrm{~Pa}$ with a strain value within the LVR $(0.01 \%)$. The storage modulus $\left(\mathrm{G}^{\prime}\right)$ represents the elastic portion of the viscoelastic behavior, which describes the solid-state behavior of the sample, whereas the loss modulus $\left(G^{\prime \prime}\right)$ characterizes the viscous portion of the viscoelastic behavior, seen as the liquid-like behavior of the sample. The magnitude of these two parameters determines the viscoelastic properties of the LM. A power model fitted the $G^{\prime}$ and $G^{\prime \prime}$ 
against $\omega$ plot. Therefore, the slope (n) in the fitting is the scaling factor of $\mathrm{G}^{\prime}$ and $\mathrm{G}^{\prime \prime}$ against $\omega$, and the intercept $(\mathrm{k})$ is the prefactor, as follows:

$$
\mathrm{G}^{\prime} \text { or } \mathrm{G}^{\prime \prime}=\mathrm{k} \times \omega^{\mathrm{n}^{\prime}}
$$

\subsubsection{Temperature Sweeps (Non-Isothermal Measurements)}

Temperature ramps were performed with a fixed frequency $(1 \mathrm{~Hz})$, strain $(0.01 \%)$, and stress value $(1 \mathrm{~Pa})$ set within LVR. Initially, the equipment was maintained at $25^{\circ} \mathrm{C}$ followed by a heating step to $80^{\circ} \mathrm{C}$, isothermally maintained for $5 \mathrm{~min}$., followed by a cooling step to $25^{\circ} \mathrm{C}$. The cross-over temperature $\left(\mathrm{G}^{\prime}=\mathrm{G}^{\prime \prime}\right)$ during cooling was defined as the gelling temperature (Tsol-gel), whereas that one at the heating stage was considered as the gel-sol transition temperature (Tgel-sol).

\subsubsection{Thixotropy (Isothermal Measurement)}

The capacity of the matrix systems to recover structure after shear was evaluated utilizing thixotropic recovery tests. First, the samples were subjected to two consecutive cycles of shear rates from $0.1 \mathrm{t} 0100 \mathrm{~s}^{-1}$ with step time of $10 \mathrm{~s}$ and then maintained at $100 \mathrm{~s}^{-1}$ for $5 \mathrm{~min}$., followed by decreasing rate to $0.1 \mathrm{~s}^{-1}$. The recovery percentage was calculated by comparing the AUC from the increasing and decreasing shear rate steps. Flow curves were fitted to the general Herschel-Bulkley model with three parameters using the Statgraphics ${ }^{\circledR}$ software. Further, the Creep test was conducted at two stages. The first one submitting the samples to a constant stress of $50 \mathrm{~Pa}$ for $25 \mathrm{~s}$ followed by a stress release for $25 \mathrm{~s}$ and measuring the strain change.

\subsection{Total Polyphenol Compounds}

These were determined while using the Folin-Ciocalteau reagent. $100 \mu \mathrm{L}$ of Folin-Ciocalteau reagent, $300 \mu \mathrm{L}$ of $20 \%$ sodium carbonate solution, $1.58 \mathrm{~mL}$ of DI-water, and $20 \mu \mathrm{L}$ of sample $(\sim 0.1 \mathrm{~g}$ of freeze-dried sample suspended in $30.0 \mathrm{~mL}$ of methanol) were added and mixed. The mixture was incubated at $25^{\circ} \mathrm{C}$ for $1 \mathrm{~h}$ and stored in the darkness. The resulting absorbance was measured at $725 \mathrm{~nm}$ in a UV/VIS spectrophotometer (Genesys 10S UV-VIS, Thermo scientific, CA, USA). The results were expressed as mg of gallic acid (GA) per gram of sample (mg GA/g sample).

\subsection{Ferric Reducing Antioxidant Power (FRAP)}

The FRAP was measured by taking $100 \mu \mathrm{L}$ of sample ( 0.1 mg of sample suspended in $30.0 \mathrm{~mL}$ of methanol) and then mixed with $900 \mu \mathrm{L}$ of deionized water and $2.0 \mathrm{~mL}$ of the $10 \mathrm{mM}$ FRAP reagent containing 2,4,6-tri-(2-pyridyl)-1,3,5-triazine (TPTZ), $20 \mathrm{mM} \mathrm{FeCl}_{3}-6 \mathrm{H}_{2} \mathrm{O}$ solution, and $0.3 \mathrm{mM}$ acetate buffer at $\mathrm{pH} 3.6$ and 1:1:10 ratio, respectively. The mixture was incubated at $37^{\circ} \mathrm{C}$ for $30 \mathrm{~min}$. The absorbance was then measured at $593 \mathrm{~nm}$ in a UV/VIS spectrophotometer (Genesys 10S UV-VIS, Thermo scientific, CA, USA). A Trolox ${ }^{\circledR}$ calibration curve was used and the results were expressed as $\mu \mathrm{mol} \mathrm{TE} / \mathrm{Kg}$.

\subsection{Antioxidant Activity (ABTS•+ Method)}

The ABTS assay was performed by taking $100 \mu \mathrm{L}$ of sample (diluted appropriately with methanol) and then mixed with $1 \mathrm{~mL}$ of ABTS $\bullet+$ solution. The degraded color spectrum was determined after $30 \mathrm{~min}$. at $730 \mathrm{~nm}$ while using a spectrophotometer (UV-1700, Shimadzu ${ }^{\circledR}$, Kyoto Japan). A Trolox ${ }^{\circledR}$ calibration curve was conducted for quantification purposes and the results were expressed as Trolox ${ }^{\circledR}$ equivalents (TE) or $\mu \mathrm{mol} \mathrm{TE} / \mathrm{Kg}$.

\subsection{Functional Properties}

The CIELAB color profile was executed on an Nh310 color meter (Skyworth, Inno Valley, Shenzhen, China). Briefly, the melted samples were poured on a transparent glass slide $(2.5 \times 7.5 \mathrm{~cm}$ size $)$ rendering 
a $2 \mathrm{~mm}$ thickness once solidified at $4{ }^{\circ} \mathrm{C}$ for $5 \mathrm{~min}$. These slides were then placed on a white surface and measurements were taken on top of the surface. The extensibility analysis was conducted by taking $50 \mathrm{mg}$ of sample and applying a glass tile on top at a constant weight $(250 \mathrm{~g})$. Subsequently, the $\mathrm{x}$ and $\mathrm{y}$ radius were taken with a digital caliper and the area of the respective ellipse was calculated. The volatile retention capacity was determined by thermogravimetry heating the previously weighed samples at $40^{\circ} \mathrm{C}$ for $15 \mathrm{~min}$., followed by measurement of the sample weight. The percentage weight difference was taken as the volatile retention capacity.

\subsection{Statistical Analysis}

The analysis was performed using the Statgraphics ${ }^{\circledR}$ centurion XVI software. Differences among treatment means were tested using Fisher's least significant difference test $(p<0.05)$.

\section{Results and Discussion}

\subsection{Crystallization Behavior}

Figure 1 depicts the wide angle $\mathrm{X}$-ray difractograms of neat waxes. Most waxes showed a degree of crystallinity (DC) ranging from 67 to $71 \%$, except for beewax (BEW). The lower DC in BEW is attributed to the poor crystal network ordering of the solid phase, due to the diverse presence of esters, fatty acids (FAs) and hydrocarbons (HCs). The last two families of compounds introduced a greater disorder conferring the lowest melting temperature of $37.8^{\circ} \mathrm{C}$ (Table 2). Thus, BEW had the weakest and less stable crystal structure. On the contrary, carnauba wax (CRW) has virtually no hydrocarbon compounds prevailing wax ester (WEs) compounds, rendering a more ordered system resulting in a large DC and melting temperature $\left(82^{\circ} \mathrm{C}\right)$. All of the waxes exhibited very similar wide angle diffraction patterns with one strong reflection (110) peak at $0.28 \mathrm{~nm}$, followed in intensity by a second peak at $0.31 \mathrm{~nm}(200)$. The (110) reflection peak corresponds to a triple chain length stacking (3L), while the other peak (200) is indicative of a $2 \mathrm{~L}$ packing. These results indicate a $\beta$ orthorhombic crystalline sub-cell arrangement that is known to be the most stable allomorph [17].

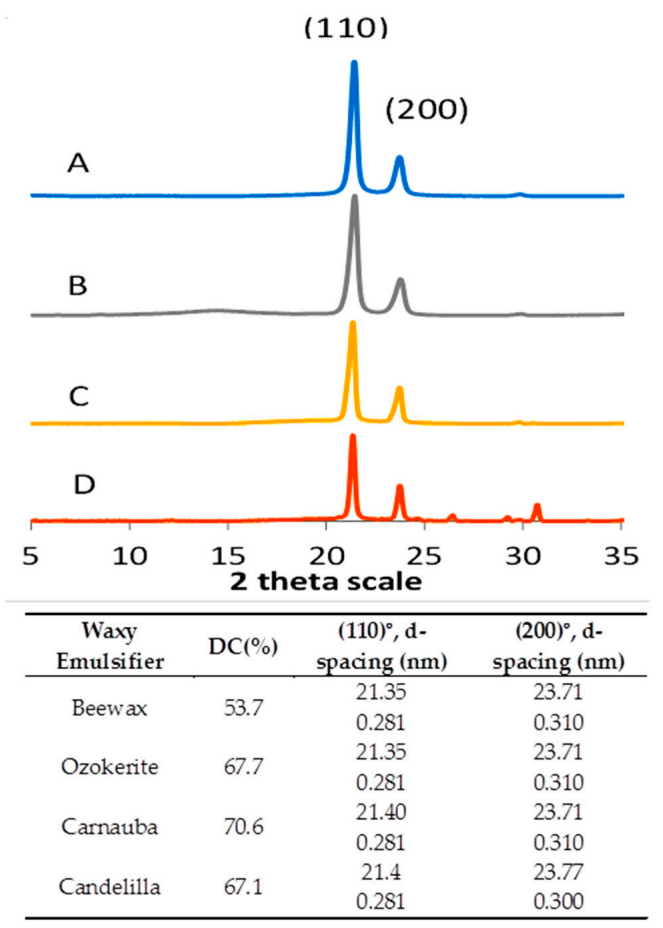

Figure 1. Wide angle $X$-ray diffraction for waxy emulsifiers. (A). carnauba wax, (B). candelilla wax, (C). beewax, (D). ozokerite wax, (DC). Degree of crystallinity. 
Table 2. Thermal parameters obtained from the DSC profiles.

\begin{tabular}{|c|c|c|c|c|c|c|c|c|c|}
\hline $\begin{array}{l}\text { Neat Wax or } \\
\text { Lipidic Matrix } \\
\text { System }\end{array}$ & $\operatorname{Tm}$ Onset $\left({ }^{\circ} \mathrm{C}\right)$ & $\operatorname{Tm}\left({ }^{\circ} \mathrm{C}\right)$ & $\operatorname{Tm} m_{\text {offset }}\left({ }^{\circ} \mathrm{C}\right)$ & $\mathrm{Tc}$ onset $\left({ }^{\circ} \mathrm{C}\right)$ & Tc $\left({ }^{\circ} \mathrm{C}\right)$ & $\mathrm{Tc}$ offset $\left({ }^{\circ} \mathrm{C}\right)$ & $\Delta \mathrm{T}\left({ }^{\circ} \mathrm{C}\right)$ & $\begin{array}{c}\Delta \mathrm{Hm} \\
(\mathrm{J} / \mathrm{g})\end{array}$ & $\begin{array}{l}\Delta \mathrm{Hc} \\
(\mathrm{J} / \mathrm{g})\end{array}$ \\
\hline BEW & 31.4 & 37.8 & 43.8 & 57.7 & 53.9 & 48.5 & 9.3 & 26.0 & 0.8 \\
\hline \multirow{2}{*}{ CLW } & 25.7 & 29.3 & 33.2 & 57.0 & $55.9^{*}$ & 45.4 & 23.8 & 5.6 & 1.3 \\
\hline & 55.5 & 67.4 & 72.3 & 65.7 & 61.0 & 57.0 & 6.6 & 6.6 & 1.6 \\
\hline CRW & 60.0 & 82.0 & 85.0 & 71.7 & 61.5 & 51.7 & 17.0 & 13.3 & 0.4 \\
\hline OKW & 70.1 & 76.6 & 79.0 & 65.8 & 64.0 & 57.9 & 13.2 & 29.2 & 1.1 \\
\hline BEW matrix & 51.5 & 56.7 & 60.4 & 60.8 & 55.0 & 46.7 & 0.4 & 3.4 & 0.7 \\
\hline \multirow{3}{*}{ CLW matrix } & 21.3 & $29.5 *$ & 32.2 & \multirow{3}{*}{40.5} & \multirow{3}{*}{32.0} & \multirow{3}{*}{19.0} & \multirow{3}{*}{8.3} & 0.6 & \multirow{3}{*}{3.1} \\
\hline & 32.3 & $37.8^{*}$ & 45.1 & & & & & 1.64 & \\
\hline & 45.4 & 50.5 & 54.5 & & & & & 0.34 & \\
\hline CRW matrix & 37.0 & 49.4 & 54.8 & 61.0 & 54.7 & 47.2 & 6.2 & 0.4 & 0.4 \\
\hline OKW matrix & 36.7 & 56.5 & 78.7 & 59.6 & 58.5 & 48.7 & 19.2 & 18.1 & 0.2 \\
\hline
\end{tabular}

Figure 2 depicts the thermograms that result from the crystallization profile (dotted lines) and melting profile (straight lines) of the neat waxes (left panel) and their matrix systems (right panel).

The presence of different peaks is related to the heterogeneous chemical nature of the lipidic matrixes. For instance, CRW is mainly composed by several types of WEs forming one large and wide melting event, whereas other materials, such as BEW and candelilla wax (CLW), also had a considerable amount of low molecular weight HCs, FAs, and fatty alcohols (FAls), which resulted in melting events at lower temperatures. Thus, BEW showed a broad and intense melting peak at $37.8{ }^{\circ} \mathrm{C}$ due to the short-chain FAs, mostly stearic acid $\mathrm{C}_{18}$, oleic acid $\mathrm{C}_{18: 1}$, and palmitic acid $\mathrm{C}_{16}$, whereas at $57.9^{\circ} \mathrm{C}$ showed a broad band probably attributed to the long chain WEs and HCs fraction. Interestingly, neat OKW is considered to be a mono-component wax, mainly comprised in $92 \%$ of $\mathrm{HCs}$ (Table 1), which explains the intense and narrow melting peak at a high temperature $\left(76.6^{\circ} \mathrm{C}\right)$ probably attributed to ceresin and resin fractions. Conversely, CLW exhibited two intense endothermic peaks at 29.3 and $67.4{ }^{\circ} \mathrm{C}$, which could be due to melting of low molecular weight FAs and FAls fractions, and mid melting point compounds, such as HCs and WEs, respectively. Further, OKW showed a large fusion enthalpy that was attributed to the small steric interference of ceresin cyclic rings, petroleum resins, and alkane compounds favoring the formation of a compact structure.

On the other hand, the crystallization peaks of neat waxes were smaller in magnitude than the melting peaks. The presence of more than a single exothermic peak is also a result of the heterogeneous chemical composition. BEW, CRW, and OKW upon cooling crystallize, showing small bands without co-crystallization. Thus, crystallization in two different stages is a consequence of the degree of crystalline disorder, since, first, a group of compound crystals (mainly long chain WEs) is formed at a high temperature $\left(68-71{ }^{\circ} \mathrm{C}\right)$, and then at a lower amount of energy a second arrangement by another set of compounds complete the crystal network. This could result from hindered crystal growth, due to the low compatibility between major and minor components. The second and most important exothermic peak of BEW and CRW is shown at 53.9 and $61.5^{\circ} \mathrm{C}$, respectively, being possibly ascribed to the crystallization of the FAc and FAl fraction, respectively [24]. 

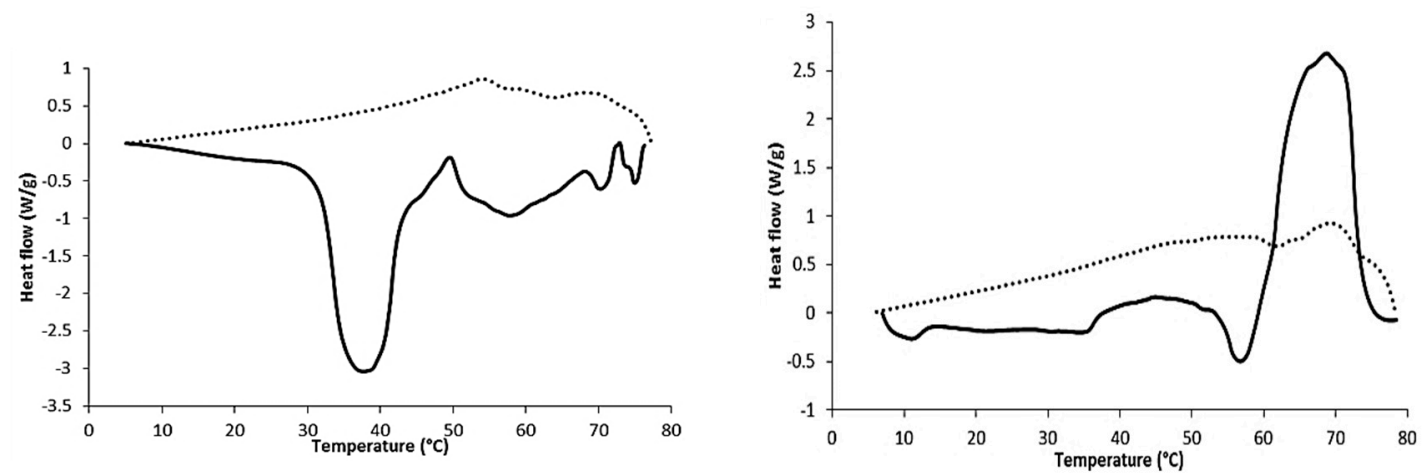

(a)
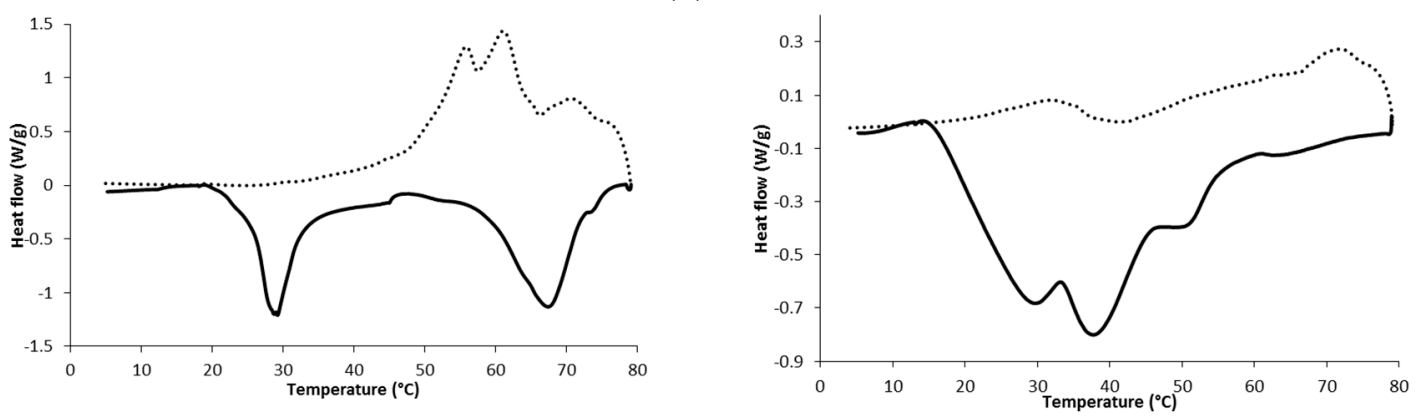

(b)
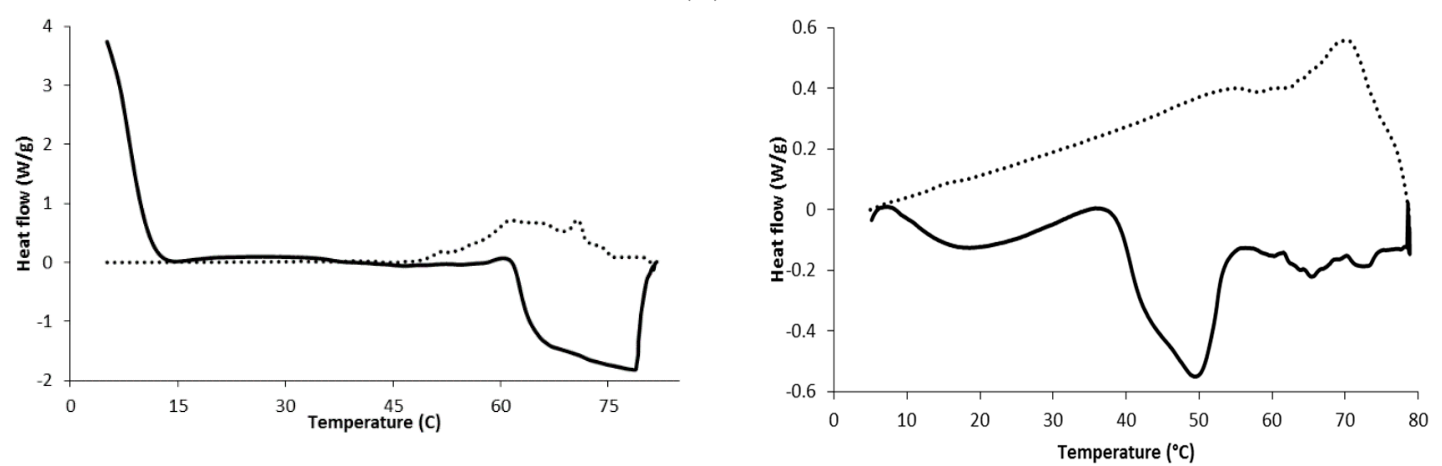

(c)
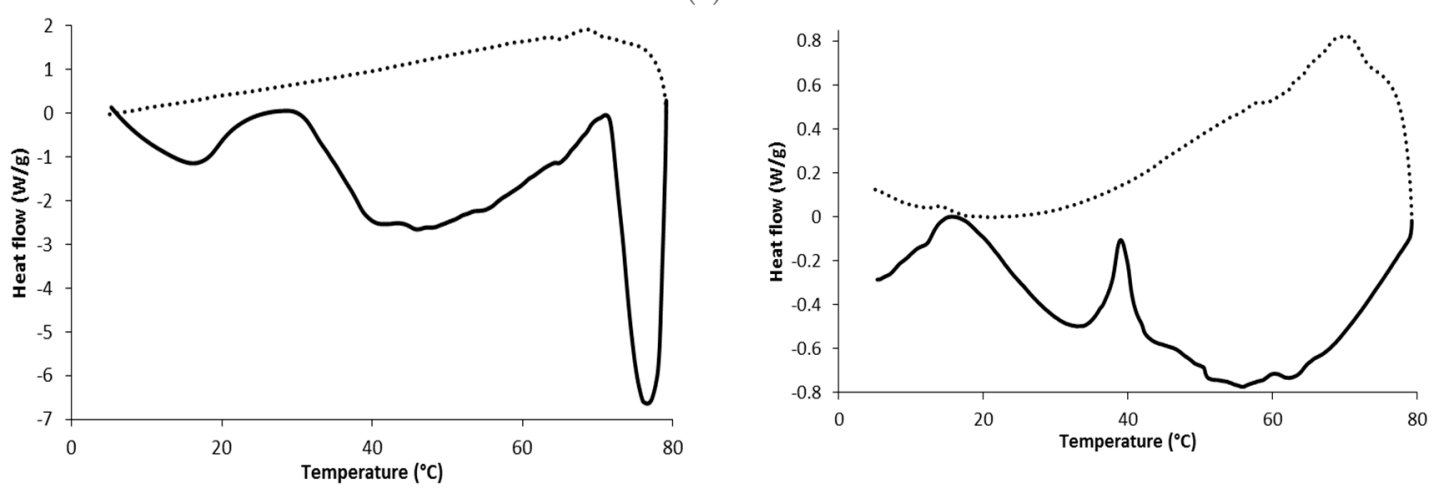

(d)

Figure 2. Differential scanning calorimetric profiles of neat waxes (left panel) and their lipidic matrix systems with lemon oil (right panel). Straight and dotted lines correspond to the heating and cooling modes, respectively. (a) beewax, (b) candelilla wax, (c) carnauba wax, and (d) ozokerite wax.

On the other hand, CLW displayed multiple crystallization temperatures increasing the co-crystallization exothermic peak at $61.0{ }^{\circ} \mathrm{C}$, followed by a small shoulder at $55.9{ }^{\circ} \mathrm{C}$. During cooling, minor components, such as n-alkanes, nonacosane, and tritriacontane, form mixed molecular 
structures with the major alkane component, hentriacontane. This interaction affects molecular packing, which results in a broader co-crystallization peak. Thus, polar components such as FAls, FAs and WEs are able to align and partially co-crystallize. This alignment is driven by the formation of hydrogen bonds [29].

The right panel in Figure 2 shows the thermograms that resulted from the lipidic matrix systems. They are shown as amorphous systems. LEO has one big endothermic event at $45.4{ }^{\circ} \mathrm{C}$ (not shown), but, once incorporated into a matrix system, this peak shifted and appeared broad, except for BEW. Thereby, the relative close endothermic events between LEO and BEW $\left(37.8^{\circ} \mathrm{C}\right)$ suggest that both substances are highly miscible and that only a minimal co-crystallization occurs when these two substances are incorporated into the matrix. The HC, WEs, and FAl fraction of the CLW matrix eased crystallization at low temperatures. Matrixes having poor interaction with the terpenoids of LEO showed very little crystallization due to the poor molecular organization. In turn, it caused two small exothermic peaks. The first one was initiated by the supersaturation of waxes in the matrix, followed by a second peak indicating complete crystallization. The magnitude of these two events depended on the wax chemical composition.

The energy that was required to crystallize and melt these matrix systems was smaller than that of the neat wax, which can be seen from enthalpy values. The melting enthalpy is a measurement of the amount of crystalline mass in these matrixes and depended on the wax chemical composition. The low activation energy that is required for melting these matrixes is explained by the relative level of solubility of the waxes in liquid LEO. Thus, BEW and OKW and their respective matrixes exhibited the largest solubility and, hence, melting enthalpy. On the other hand, CLW and its matrix system showed the largest crystallization enthalpy indicating a high resistance to temperature changes due to the high fraction of HCs, and WEs crystals formed.

The difference in temperature $(\Delta \mathrm{T})$ between $\mathrm{Tm}_{\text {offset }}-\mathrm{Tc}_{\text {onset, }}$ largely depended on the wax chemical composition. In neat waxes, CLW and CRW showed the largest $\triangle \mathrm{T}$, whereas BEW and OKW showed the lowest $\Delta \mathrm{T}$ indicating a slow and rapid crystal formation, respectively. In contrast, OKW matrix systems had the largest $\Delta \mathrm{T}$ values, suggesting a slower network formation due to the large content of cyclic HCs. Interestingly, the BEW matrixes showed the poorest recrystallization behavior.

The low melting and crystallization enthalpies of these matrixes are explained by the interaction of wax and LEO components. Thus, limonene, which is the major component of LEO, has a large non-polar nature inhibiting the efficient ordering imparted by the waxes forming a less ordered structure. Particularly, BEW and OKW compounds showed the largest affinity (van der Waals interactions) towards non-polar LEO molecules, resulting in a rapid solvatation. Thus, the single ring of limonene intermingled with hydrocarbon molecules hindering their efficient ordering during the cooling process avoiding the growth of large crystalline networks. On the other hand, in CLW and CRW matrixes the limonene ring interferes with the solubilization of WEs resulting in larger crystal growth. This reduced interaction is explained by the flat and more condensed cyclic core of limonene, preventing, to some extent, interactions with the WEs and FAs, so they cannot solvate easily while being incorporated into the matrix crystal structure in several stages [30].

\subsection{Isothermal Oscillatory Rheological Behavior}

Oscillatory rheological measurements allow for the classification of matrix strength based on three factors: the difference between $G^{\prime}$ and $G^{\prime \prime}$, the average value of $G^{\prime}$ within the linear viscoelastic region (LVR, $\mathrm{G}_{\mathrm{LVR}}^{\prime}$ ), and the length of the linear region of the curve. Therefore, these matrixes could be categorized as strong $\left(G^{\prime \prime} / G^{\prime}<0.1\right)$, weak $\left(0.1<G^{\prime \prime} / G^{\prime}<1\right)$, or viscous sols $\left(G^{\prime \prime} / G^{\prime}>1\right)$.

Figure 3a shows that $\mathrm{G}^{\prime}$ was higher than $\mathrm{G}^{\prime \prime}(>50 \mathrm{~Pa})$ within LVR indicating a gel-like property, and the CRW matrixes showed the largest oscillation strain limit (plateau region) of $0.32 \%$ and 2676100 $\mathrm{Pa}$, respectively (Table 3). This critical point in LVR at which the curve of $\mathrm{G}^{\prime}$ begin to deviate noticeable from the LVR $(10 \%)$, provide information regarding the stability under strain sweep. Thus, the CRW matrix had the largest ductility and structural resistance to the applied strain when compared to 
other matrixes. Beyond the critical point, matrixes undergo permanent deformation, as reflected from the abrupt decrease in the $G^{\prime}$ and $G^{\prime \prime}$ values. This can be explained by a partial breakup of the matrix network triggering flow characteristics. Subsequently, at the cross-over point, the gel phase is transformed to a viscous sol $\left(G^{\prime}=G^{\prime \prime}\right)$. CRW showed the highest $G^{\prime}$ at cross-over point suggesting a strong and a more stable network. The zone spanning between critical point and cross-over point is referred to as the yield zone and the CRW matrix had a large zone mainly attributed to the presence of mixtures of aliphatic esters and $p$-hydroxyl-cinnamic aliphatic diesters [29]. Furthermore, the CRW matrix was considered to be the only strong matrix since $G^{\prime \prime} / G^{\prime}$ was always lower than 0.1 , demonstrating that the solid-like properties strongly dominated over the liquid-like characteristics. Likewise, the CLW matrix displayed the second largest $G^{\prime}$ at critical point, although it showed the largest fall in $\mathrm{G}^{\prime}$ with strain, reaching a cross-over point of $41659 \mathrm{~Pa}$. Conversely, the OKW and BEW matrixes were much softer and yielded at much lower strain.

Matrixes were then subjected to a frequency sweep in order to investigate their time dependent behavior (Figure 3b). Most of the matrixes showed a slight dependence on frequency from 0.1 to $100 \mathrm{rad} / \mathrm{s}$, as indicated by a slightly positive slope at $\mathrm{G}^{\prime}$ and $\mathrm{G}^{\prime \prime}$ curves, especially for BEW matrixes, which is characteristic of weak networks. Other curves were mostly linear with $G^{\prime}>G^{\prime \prime}$, indicating that these matrixes had good tolerance to the rate of deformation and that bonds forming the network were almost permanent within the time frame of the performed test. The poor fitting of CRW and CLW matrixes shown by an almost parallel trend with the $x$-axis indicates long-term stability at resting conditions. In contrast, the OKW matrix displayed a cross-over point between $\mathrm{G}^{\prime}$ and $\mathrm{G}^{\prime \prime}$ at low frequencies, indicating poor stability due to its weak colloidal nature where the viscoelastic behavior is elastic dominated at low frequencies $(<1.6 \mathrm{rad} / \mathrm{s})$, but viscous dominated at larger frequencies. Thereby, this matrix system was unstable at low amplitudes leading to the breaking up of the internal structure. 


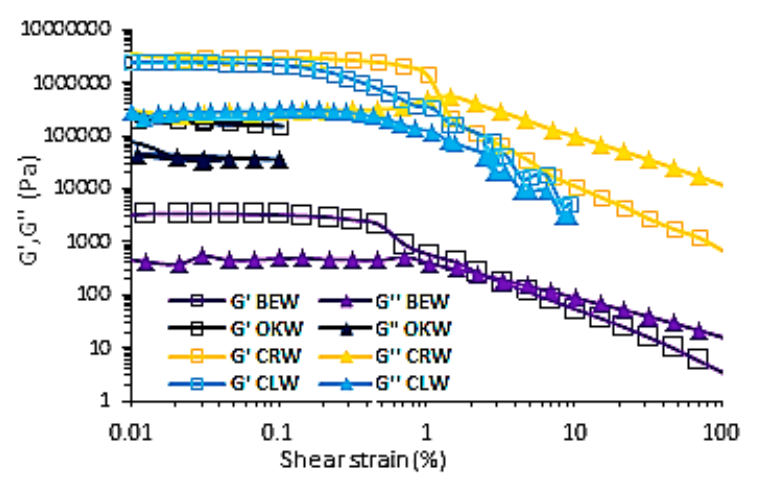

(a)

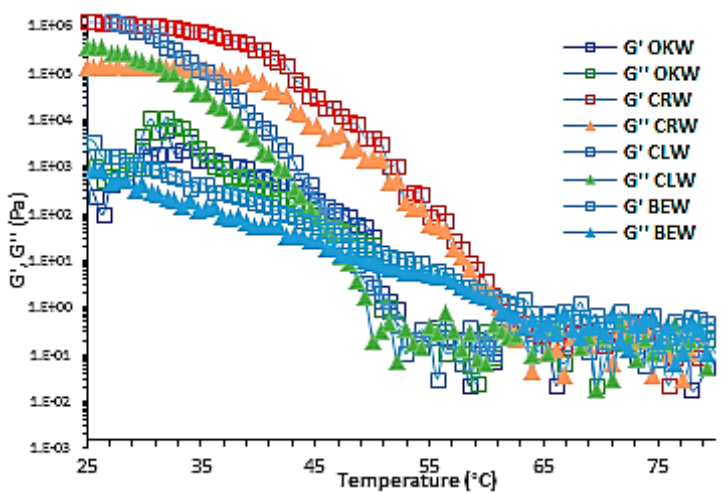

(c)

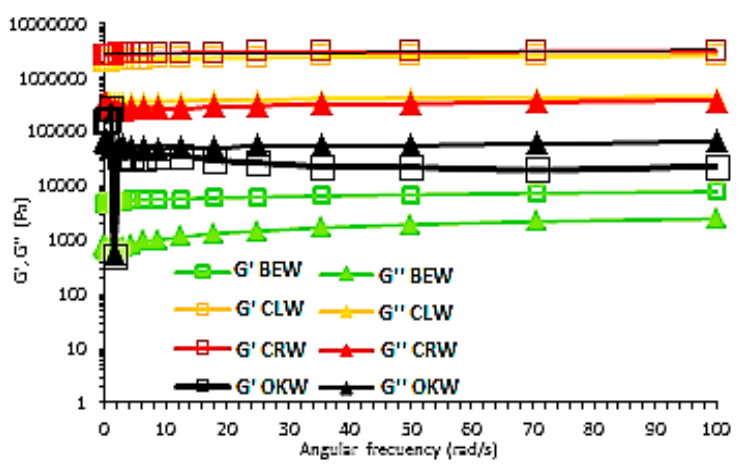

(b)

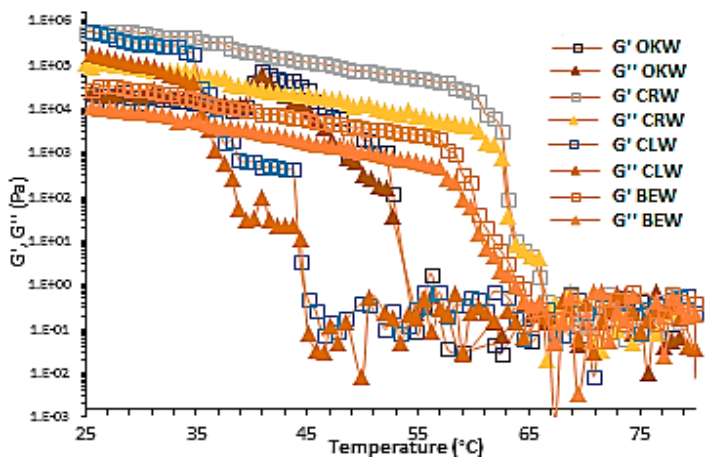

(d)

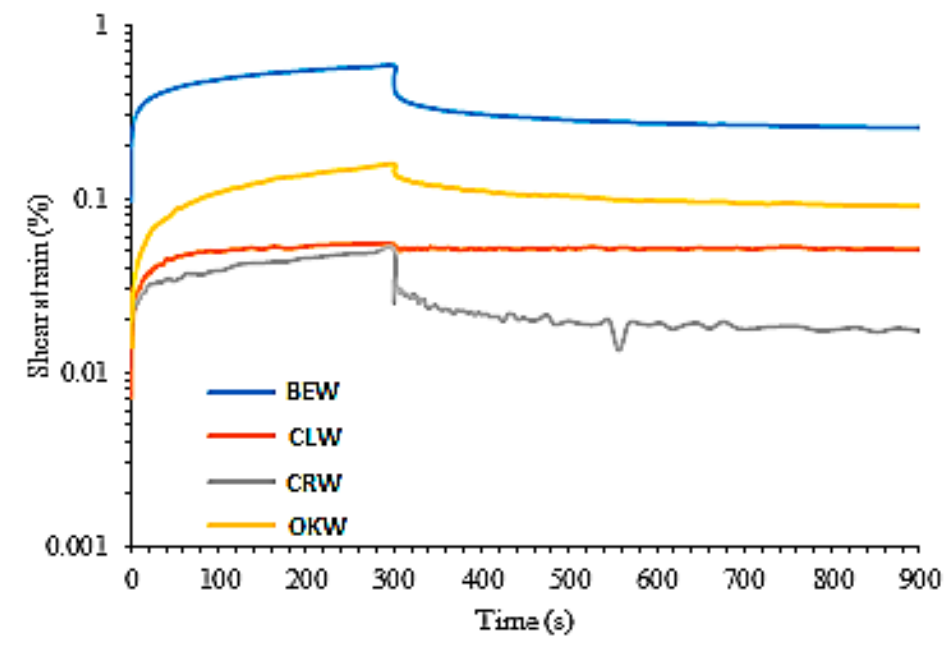

(e)

Figure 3. Linear viscoelastic region (a); frequency sweep curves (b); heating temperature sweep (c); cooling temperature sweep $(\mathbf{d})$; creep test of matrix systems (e); produced with representative waxes: $\mathrm{BEW}$, beewax matrix; CRW, carnauba matrix; CLW, candelilla matrix; OKW, ozokerite matrix. 
Table 3. Viscoelastic parameters obtained from the oscillation yield strain, frequency and temperature sweep tests.

\begin{tabular}{|c|c|c|c|c|c|c|c|c|c|c|c|c|}
\hline \multirow{2}{*}{$\begin{array}{l}\text { Lipidic } \\
\text { Matrix } \\
\text { System }\end{array}$} & \multirow{2}{*}{$\begin{array}{c}\text { Critical } \\
\text { Point } \\
\text { LVR }(\%)\end{array}$} & \multirow{2}{*}{$\begin{array}{l}\text { Critical } \\
\text { Stress } \\
(\mathbf{P a})\end{array}$} & \multirow{2}{*}{$\begin{array}{l}\text { Dynamic } \\
\text { Yield } \\
\text { Stress (Pa) }\end{array}$} & \multirow{2}{*}{$\begin{array}{l}\text { Average } \\
\mathrm{G}^{\prime \prime} / \mathrm{G}_{\text {LVR }}^{\prime}\end{array}$} & \multicolumn{2}{|c|}{$\begin{array}{l}\text { Temperature } \\
\text { Sweep }\end{array}$} & \multicolumn{3}{|c|}{$\begin{array}{c}\text { Angular Frequency G' } \\
\text { Power Model }\end{array}$} & \multicolumn{3}{|c|}{$\begin{array}{l}\text { Angular Frequency } \\
\text { G" Power Model }\end{array}$} \\
\hline & & & & & $\mathrm{T}_{\mathrm{G}-\mathrm{S}}$ & $\mathbf{T}_{\mathrm{S}-\mathrm{G}}$ & $\mathbf{k}_{1}$ & $\mathrm{n}_{1}$ & $\mathrm{r}^{2}$ & $k_{2}$ & $\mathbf{n}_{2}$ & $r^{2}$ \\
\hline Beewax & 0.15 & 3115.4 & 249.5 & 0.139 & 56.4 & 64.6 & 5238 & 32 & 0.9229 & 767.3 & 20.5 & 0.9417 \\
\hline Ozokerite & 0.02 & 196,350 & 279.1 & 0.211 & $\begin{array}{l}54.3 \\
36.2\end{array}$ & $\begin{array}{l}52.7 \\
40.2\end{array}$ & NA & NA & NA & NA & NA & NA \\
\hline Carnauba & 0.32 & $2,676,100$ & 557,040 & 0.096 & 64.8 & 65.0 & $3 \times 10^{6}$ & 5769.9 & 0.8013 & 289,960 & 945.7 & 0.5154 \\
\hline Candelilla & 0.10 & $2,171,700$ & 41,659 & 0.12 & 52.8 & 44.4 & $2 \times 10^{6}$ & 7109.7 & 0.7472 & 362,336 & 1080.3 & 0.8617 \\
\hline
\end{tabular}

$\mathrm{T}_{\mathrm{G}-\mathrm{S}}$ : gel-sol transition, $\mathrm{T}_{\mathrm{S}-\mathrm{G}}$ : sol-gel transition, $\mathrm{k}_{1}, \mathrm{k}_{2}$ : initial $\mathrm{G}^{\prime}$ and $\mathrm{G}^{\prime \prime}$, respectively, $\mathrm{n}_{1}, \mathrm{n}_{2}$ : rate of change in $\mathrm{G}^{\prime}$ and $G^{\prime \prime}$, respectively.

\subsection{Gelling Behavior}

The gel-sol and sol-gel transition temperatures were rheologically determined at the cross-over point from the heating and cooling curves, respectively (Figure 3c,d). At low temperatures, these lipidic matrixes exhibited higher $G^{\prime}$ values than those of $G^{\prime \prime}$ showing a dominant elastic property. During the heating phase $G^{\prime}$ and $G^{\prime \prime}$ values showed a more pronounced decrease for CLW, CRW, and OKW matrixes, whereas the BEW matrix showed a linear (constant) decrease with increasing temperature. A plateau followed by one abrupt transition (slope) is observed within the range between 50 and $65^{\circ} \mathrm{C}$ and it corresponded to the $\mathrm{T}_{\mathrm{G}-\mathrm{S}}$ phase. The wax composition was responsible for the differences in the matrix state transition. Once the cross-over point was surpassed, these curves were comparable due to the complete melting of the matrix network. Further, the $\mathrm{T}_{\mathrm{G}-\mathrm{S}}$ matched the $\mathrm{T}_{\mathrm{m}}\left(56.7^{\circ} \mathrm{C}\right)$ only for the BEW matrix, indicating that these two processes occurred almost simultaneously or one event is a consequence of the other. Thus, the $\mathrm{T}_{\mathrm{G}-\mathrm{S}}$ of this matrix was not preceded by the extensive microstructure disruption, in contrast to the other matrixes formed by waxes containing high and mid-melting components [31].

Regarding the cooling phase, below $80^{\circ} \mathrm{C}$, the solubility of the wax in LEO decreased, and a phase separation begins, and further cooling results in a complete crystallization at the cross-over point $\left(\mathrm{T}_{\mathrm{S}-\mathrm{G}}\right)$ (Figure 3d). A further cooling increases $\mathrm{G}^{\prime}$ due to the three-dimensional (3D) matrix formed by random aggregation and mutual entanglement of wax crystals within LEO. In all matrixes, early nucleation occurred between 68.9 and $70.4{ }^{\circ} \mathrm{C}$, as indicated by DSC measurements, but a true gelation started at much lower temperatures. On comparing the cross-over points the BEW matrix had a $\mathrm{T}_{\mathrm{S}-\mathrm{G}}$ very closed to the CRW matrix indicating extensive microstructure development, in contrast to the matrixes having a high content of HCs, such as CLW and OKW [32]. Further, there was a large difference between $\mathrm{T}_{\mathrm{S}-\mathrm{G}}$ and $\mathrm{Tc}$ of these matrix systems demonstrating structuration since crystal formation started. At the end of the cooling phase $\left(25^{\circ} \mathrm{C}\right), \mathrm{CRW}$ and CLW matrixes achieved a strong gelling behavior $\left(G^{\prime}-G^{\prime \prime}>1\right.$ decade), whereas OKW and BEW matrixes behaved like weak matrixes $\left(G^{\prime}-G^{\prime \prime}\right.$ $<1$ decade). Interestingly, the OKW matrix showed two transition temperatures indicating that the crystalline species took longer to develop in a sequential crystallization, probably occurring first for the large fraction of ceresin and resins followed by another cross-over point due to the mineral oil fraction.

\subsection{Isothermal Flow and Thixotropic Behavior}

The capacity of these matrixes to recover their strength after shearing input was studied by applying an increasing and decreasing shear rate cycle in a range from 0.1 to $100 \mathrm{~s}^{-1}$ with step times of $5 \mathrm{~s}$ and tracking the changes in stress at $25^{\circ} \mathrm{C}$. This test gives a clear insight into the thixotropic behavior of lipidic matrixes. All ofthe samples showed a decrease of viscosity with increasing shear rates, suggesting a sensitive nature due to the weak interactions sustaining the 3D matrix network, such as van der Waals interactions and London dispersion forces. During the decreasing shear rate step, the samples showed a very small recovery of the structure (Table 4). This structure rearrangement led to a decrease in shear stress values after shifting back to low-shear condition $\left(0.1 \mathrm{~s}^{-1}\right)$. The BEW and OKW matrixes showed the largest recovery of 41.4 and 13\%, respectively, whilst CRW and CLW 
matrixes presented the poorest recovery $(<10 \%)$. This poor recovery is explained by the structure collapse into smaller clusters of aggregates as the matrix is sheared, but with the reduction of shearing, the re-establishment of these clusters into an ordered and cohesive network is hindered, since shear forces overcame the Brownian motion of suspended crystals [33].

Table 4. Herschel-Buckley parameters and thixotropic recovery from the stress-strain profiles at $25^{\circ} \mathrm{C}$.

\begin{tabular}{cccccc}
\hline $\begin{array}{c}\text { Herschel-Buckley } \\
\text { Parameter }\end{array}$ & Beewax Matrix & $\begin{array}{c}\text { Candelilla } \\
\text { Wax Matrix }\end{array}$ & $\begin{array}{c}\text { Carnauba Wax } \\
\text { Matrix }\end{array}$ & $\begin{array}{c}\text { Ozokerite } \\
\text { Wax Matrix }\end{array}$ & $\begin{array}{c}\text { Lemon } \\
\text { Essential Oil }\end{array}$ \\
\hline$\tau_{\mathrm{o}}(\mathrm{Pa})$ & 3.7 & 150.1 & 72.7 & 0.11 & 0 \\
$\mathrm{k}(\mathrm{Pa} . \mathrm{s})$ & 5 & 168.15 & 11.19 & 31.1 & 0.001 \\
$\mathrm{n}$ & 0.19 & 0.093 & 0.491 & 0.160 & 0.97 \\
$\mathrm{R}^{2}$ & 0.9500 & 0.8000 & 0.8200 & 0.8219 & 0.9994 \\
Recovery (\%) & 41.4 & 7.6 & 9.6 & 13 & 100 \\
$\begin{array}{c}\text { Extensibility } \\
\left(\mathrm{mm}^{2}\right)\end{array}$ & $481.4 \pm 74.8$ & $293 \pm 27.2$ & $268.1 \pm 52.2$ & $446 \pm 56.9$ & N.A. \\
\hline
\end{tabular}

$\mathrm{N}$ : flow type (flow behavior index), k: consistency index, $\tau$ : shear stress for flow.

A creep test was subsequently conducted in order to confirm the above described shear results (Figure 3e). Thus, by applying a constant stress of $50 \mathrm{~Pa}$ for $25 \mathrm{~s}$, weak matrixes, such as BEW and OKW, showed a large deformation, whilst the stiff CRW and CLW matrixes showed minimal change. Once that stress ceased, most matrixes suffered from an abrupt fall of deformation showing some tendency to recovery. In this case, the BEW matrix showed the largest recovery, whereas the CLW and CRW matrixes presented a low one. Thereby, the network structure in the last two matrixes is assumed to be a random agglomeration of oblongcrystalline particles, and the local bonding strength among the aggregates might be stronger in certain regions when compared to other regions due to localized crowding of aggregates. As the matrix is deformed over time, the structure breaks down into smaller clusters of aggregates flowing, and the restructuring of these clusters into a coherent network is avoided, because the shear force overcomes the Brownian motion.

The sample flow profiles were fitted to the Herschel-Buckley model and Table 4 lists the results. This model can be used to define the degree of shear thinning $(n<1)$ or shear thickening $(n>1)$ of the matrix. Except for neat LEO, which showed a truly Newtonian behavior, all of the samples presented a pseudoplastic or shear thinning character $(n<1)$. The " $k$ " parameter measures the thickness of the fluid, which is very close to the viscosity at very low shear rates. Interestingly, the degree of shear thinning was predominant for the CLW matrix, which also exhibited the largest consistency index $(\mathrm{k})$ and yield stress for flow $\left(\tau_{\mathrm{o}}\right)$. Conversely, the BEW and OKW matrixes were very weak in strength and, hence, showed the best flow and extensibility at low shear values. Interestingly, the OKW matrix was unstable under oscillatory strain sweep disrupting at a low strain. This matrix also showed a virtual absence in yield stress, indicating an almost immediate flow under applied shear. It is also important to note that, although the minimal stress for flow of this matrix was rather low, it was still appreciably high to prevent gravitational settling of the particle network.

\subsection{Crystal Morphology and Functional Properties}

Figure 4 depicts the morphological features of the lipidic matrixes, as seen by the phase contrast and fluorescence microphotographs. The BEW matrix crystallized into very fine needles inbreeding together, which are further organized into an open aggregate-like structure. These needles were very thin, elongated, and bent having $20-40 \mu \mathrm{m}$ in length. This particular shape formed a honey comb or porous system that was responsible for the weak consistency and poor degree of crystallinity of this LM. 


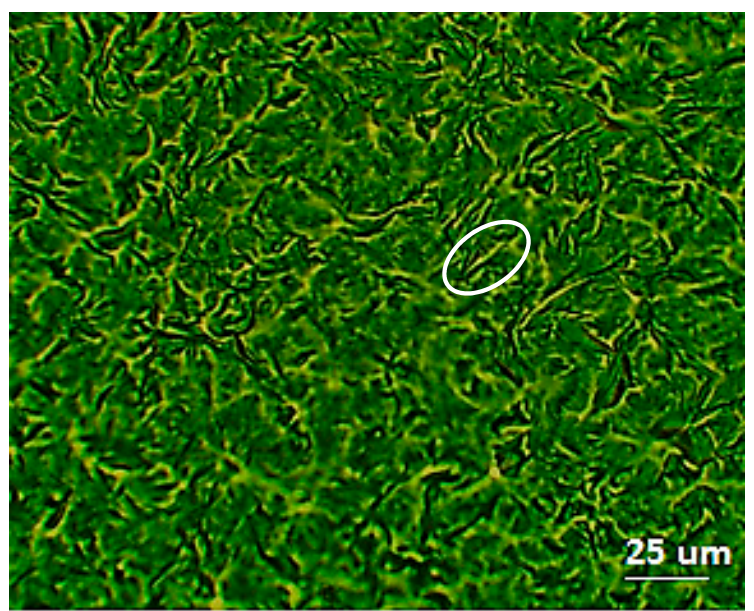

(a)

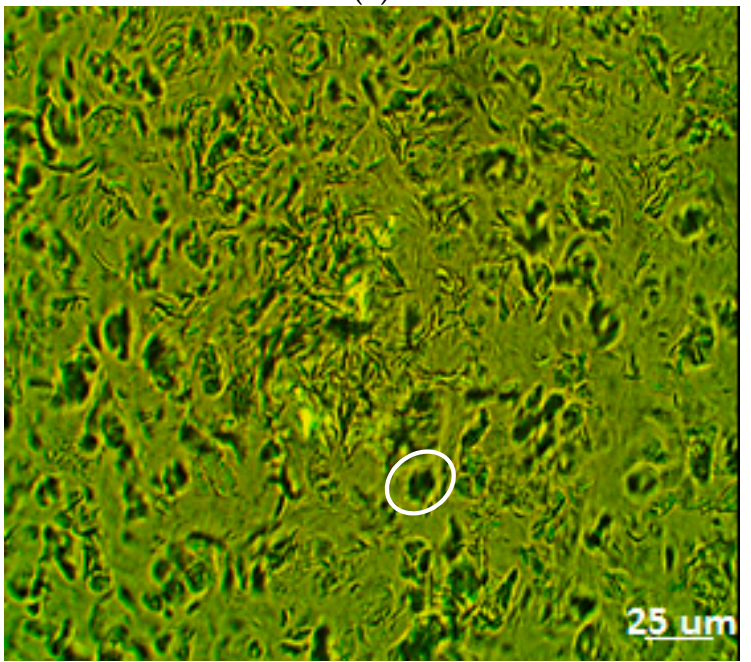

(c)

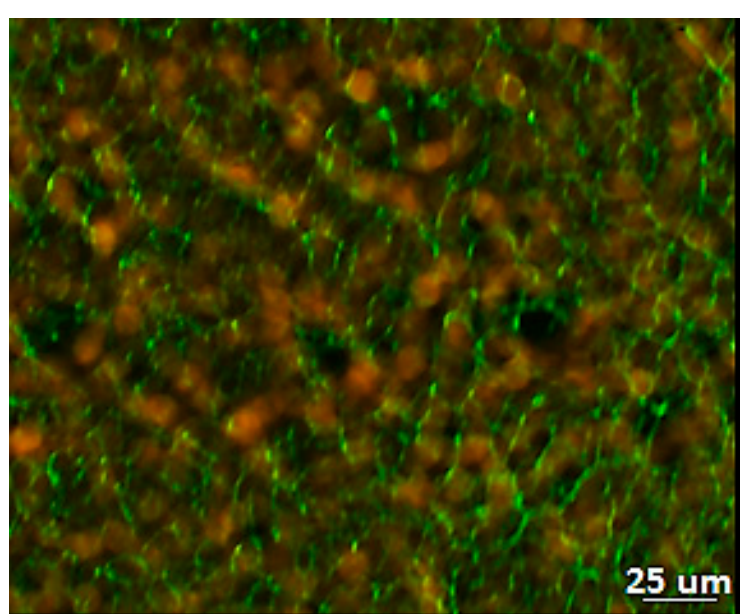

(b)

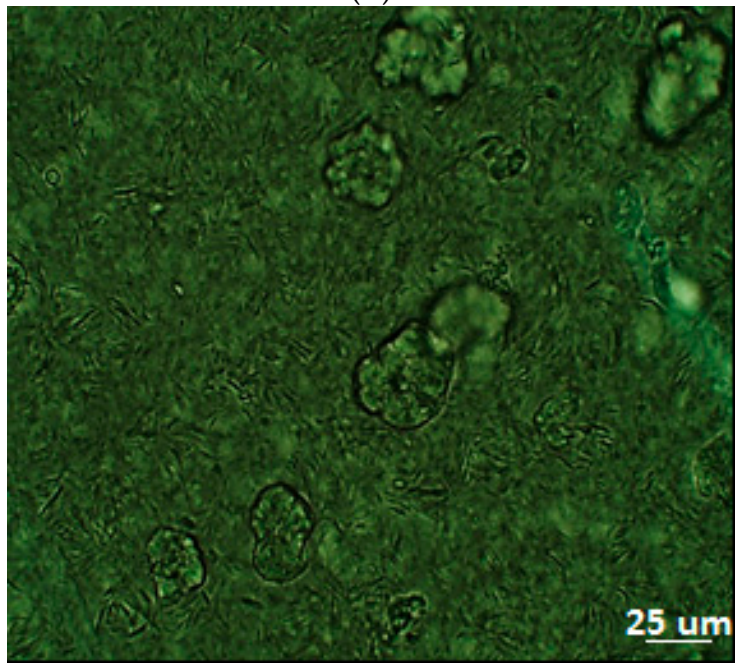

(d)

Figure 4. Cont. 


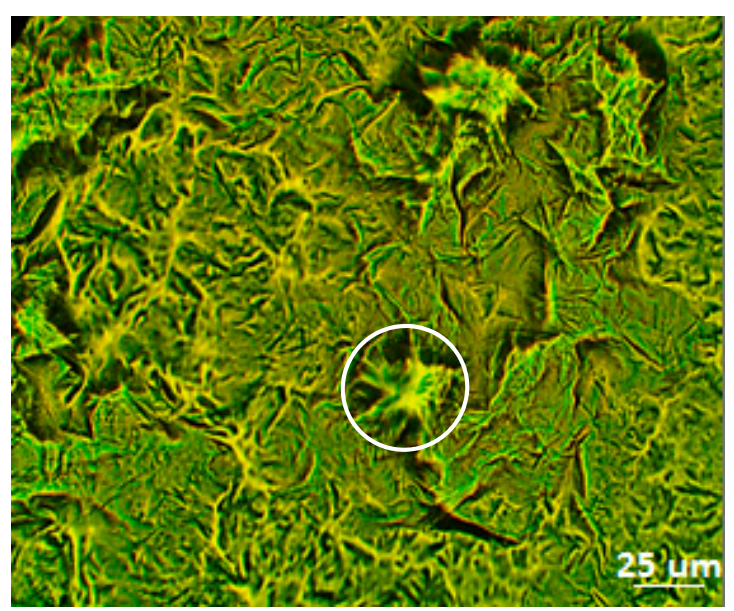

(e)

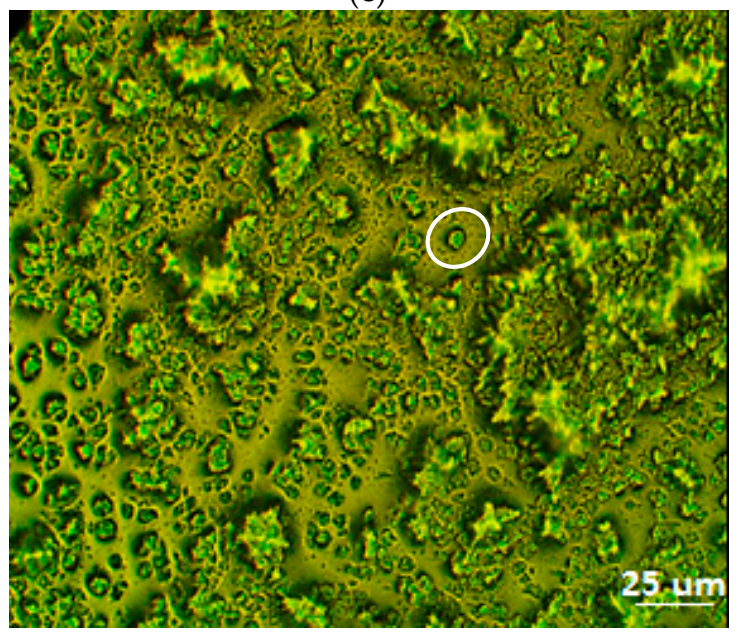

(g)

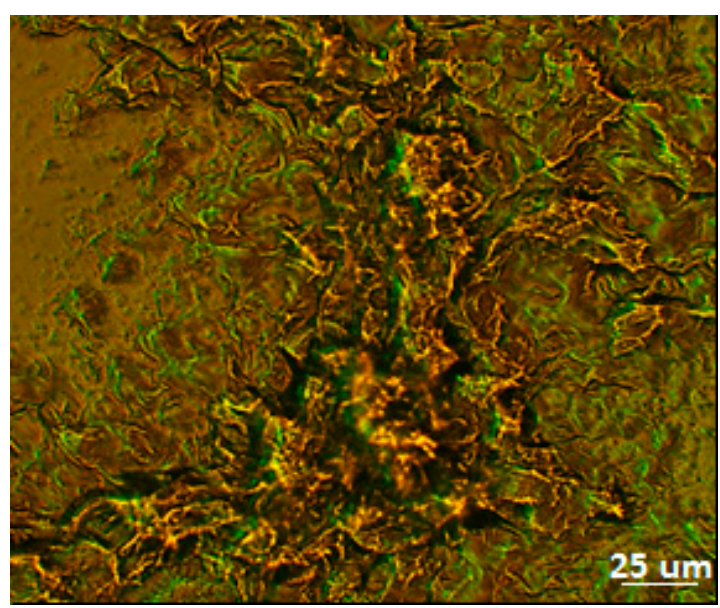

(f)

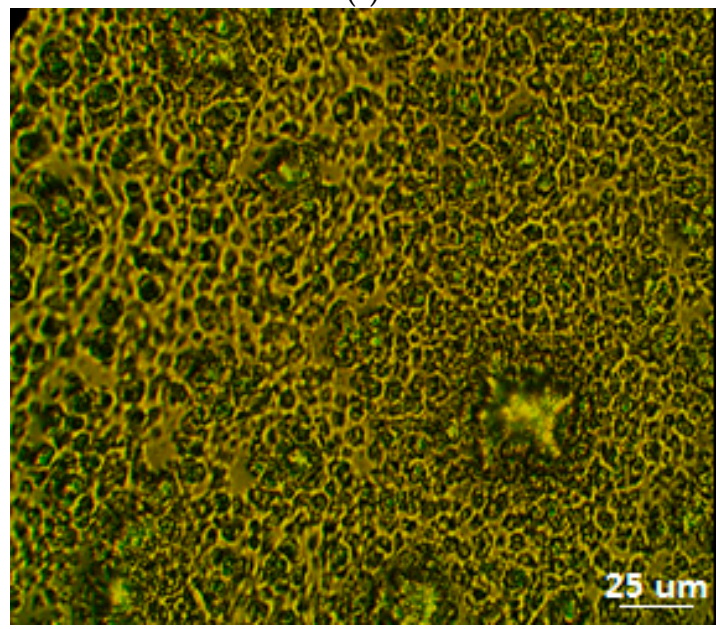

(h)

Figure 4. Phase contrast microphotographs (left panel) and fluorescence microphotographs (right panel) of lemon essential oil matrixes prepared with beewax $(\mathbf{a}, \mathbf{b})$, candelilla wax $(\mathbf{c}, \mathbf{d})$, ozokerite wax $(\mathbf{e}, \mathbf{f})$, and carnauba wax $(\mathbf{g}, \mathbf{h})$.

The CLW matrix mostly developed small oblong-like crystals rather that fibers of 5-10 $\mu \mathrm{m}$ in size. This morphology is the result of the HC components that co-crystallized with the WEs fraction during cooling. Conversely, the OKW matrix was composed of stacked crystals of $\sim 10 \mu \mathrm{m}$ in size forming larger aggregates $(50-100 \mu \mathrm{m})$ resembling a sea urchin morphology. This phenomenon might be attributed to a two-stage crystallization process that was initiated by a three-dimensional nucleation center followed by the organization of needle-like crystals in the outer layer, resulting in striated growth. Those crystals tend to pile upon each other, forming clusters.

The CRW matrix had an anisotropic, grain-like morphology with length ranging from 5 to $10 \mu \mathrm{m}$. This material exhibited a high content of WEs, which could be responsible for the excellent strength of such matrix. During cooling, the crystalline particles at the junction zones and within the network have reorganized their molecular packing and achieved a higher level of structural organization. Therefore, their crystals appear to be denser and they exhibited the largest degree of crystallization.

Table 5 lists the color characterization, volatile retention capacity, and antioxidant activity of these LM. The chemical nature of the waxy components in each LM was the factor that determined the color qualities of the samples. For instance, CRW and OKW matrixes showed the most opaque appearance, probably due to the large content of hydrocarbons. In turn, the largest fraction of hydrocarbons in OKW matrix resulted in the largest chroma (c) and hue (h) characteristics. Further, 
independent of the wax type, all LM had a volatile oil retention larger than $98 \%$, confirming a large and stable structuring for LEO.

Table 5. Functional properties (color characteristics, volatile retention, and antioxidant activity) of lipidic matrixes.

\begin{tabular}{|c|c|c|c|c|c|c|c|c|c|}
\hline \multirow[b]{2}{*}{$\begin{array}{l}\text { Lipidic Matrix } \\
\text { or Essential } \\
\text { Oil }\end{array}$} & \multicolumn{5}{|c|}{ Color Characteristics } & \multicolumn{3}{|c|}{ Antioxidant Properties* } & \multirow[b]{2}{*}{$\begin{array}{l}\text { Volatile } \\
\text { Retention } \\
\quad(\%)\end{array}$} \\
\hline & $\mathbf{L}$ & $\mathbf{a}$ & $\mathbf{b}$ & c & $\mathbf{h}$ & $\begin{array}{c}\text { Total } \\
\text { Phenolic } \\
\text { Compounds } \\
\text { (mg Gallic } \\
\text { Acid/g) }\end{array}$ & $\begin{array}{c}\text { FRAP } \\
(\mu \mathrm{g} \\
\text { Trolox/g) }\end{array}$ & $\begin{array}{c}\text { ABTS } \\
\text { (mg } \\
\text { Trolox/g) }\end{array}$ & \\
\hline Beewax & $80.6 \pm 1.4$ & $3.9 \pm 0.4$ & $18.8 \pm 2.8$ & $19.2 \pm 2.8$ & $78.2 \pm 0.6$ & 3.5 & 4272.1 & 0.37 & 98.7 \\
\hline Candelilla & $81.4 \pm 2.5$ & $\begin{array}{l}0.3 \\
0.1\end{array}$ & $13.7 \pm 5.0$ & $13.7 \pm 5$ & $89.1 \pm 2.0$ & 3.9 & 4516.6 & 0.2 & 99.1 \\
\hline Carnauba & $77.2 \pm 1.4$ & $\begin{array}{l}0.2 \\
0.1\end{array}$ & $20.9 \pm 2.4$ & 21.02 .5 & $88.5 \pm 1.5$ & 3.8 & 4307.2 & 0.12 & 98.5 \\
\hline Ozokerite & $80.9 \pm 1.3$ & $0.2 \pm 0.1$ & $1.6 \pm 0.3$ & $40.7 \pm 2.9$ & $96.6 \pm 3.3$ & 3.8 & 4415.6 & 0.37 & 98.9 \\
\hline LEO & N.A. & N.A. & N.A. & N.A. & N.A & 2.3 & 3056.5 & 0.01 & N.A \\
\hline Initial level & N.A. & N.A. & N.A. & N.A. & N.A & 4.6 & 5135.6 & 0.72 & N.A \\
\hline
\end{tabular}

On the other hand, the residual antioxidant activity that was conducted by the FRAP and ABTS methods showed a more stable behavior (up to 20-fold increase) than that obtained for the raw LEO, irrespective of the waxy material employed. Thus, it is plausible that, during storage at $50{ }^{\circ} \mathrm{C}$ for seven days, oil compounds, such as limonene, pinene, terpineol, and mircene, largely oxidized as compared to the compounds entrapped within the LM. The antioxidant activity was mostly preserved in LM containing waxy materials having a large content of hydrocarbons, such as CLW and OKW matrixes, whereas the BEW matrix having the largest content of fatty acids showed a low antioxidant activity, according to the FRAP results. This behavior might be explained by the formation of oxidative species in BEW matrixes. Further, there was no relationship between the color parameters and antioxidant characteristics of LM.

There was a large difference between the antioxidant values that were obtained from the FRAP and ABTS methods. This difference is explained by the low solubility of the ABTS reagent towards the lipophilic compounds, resulting in a partial complexation with the phenolic compounds. The high antioxidant ability of LM is explained by ROS scavenging and the inhibition of radicals and lipid peroxidation products. Further, the LEO capability to quench hydroxyl radicals and prevent oxidative damage is reduced to a $60 \%$ upon exposure to heat, and it was related to the reduction of polyphenol compounds that were initially present in the sample. The FRAP test denotes the power of antioxidants as reductants in the redox colorimetric reaction quantifying the ability of antioxidants to reduce ferric (III) ions to ferrous (II) ions at acidic pH. The higher the FRAP values, the higher the total antioxidants [9]. The results indicate a high correlation between total phenolic compounds with FRAP values $\left(r^{2}=0.9807\right)$, suggesting that phenolic compounds in LEO highly contributed to the reduction of ferric ions to ferrous ions and free radical scavenging. These phenolic compounds act as antioxidants in the LM, because they stabilize radicals that prevent the oxidation of various waxy compounds, especially fatty acids [34]. This antioxidant activity might be ascribed to the presence of oxygenated monoterpenes, followed by monoterpene hydrocarbons and sesquiterpenes. In turn, these phenolic compounds may be able to inhibit oxidant enzymes of the body, such as nitric oxide synthase, lipoxygenase, xanthine oxidase, cyclooxygenase, NADPH oxidase, and myeloperoxidase, which play an important role in redox reactions that lead to the generation of ROS. The indirect long term result could be mirrored in an antiaging effect [35]. 


\section{Conclusions}

The diverse chemical composition of lipidic matrixes resulted in different crystallization profiles and improved lemon essential oil stability by inhibiting the lipid peroxidation and scavenging of proton, oxy, and hydroxyl radicals. The physicochemical properties of these matrixes were limited by the innate chemical composition of waxy materials. Thus, the predominant short-chain FAs in BEW resulted in the most amorphous and highly flowing matrix, whereas the high amount of long-chain WEs in the CRW matrix resulted in a very high crystalline and strong material. Waxy materials can be employed for the formulation of topical preparations, with this oil having a modulated texture, cleansing, and antioxidant properties.

Author Contributions: Conceptualization, J.R.; research, writing-original draft preparation, S.C. and A.N.; writing-review and editing, and Supervision, J.R. and G.C.; funding acquisition. All authors have read and agreed to the published version of the manuscript.

Funding: This work was sponsored by Colciencias through the grant 755-2017 for the formation of Colombian PhDs. The authors also thank the committee for the development of research (CODI) of University of Antioquia and its Sustainability Strategy Program (2018-2019) for their financial support.

Conflicts of Interest: The authors declarer no conflict of interest. The funders had no role in the design of the study; in the collection, analyses, or interpretation of data; in the writing of the manuscript, or in the decision to publish the results.

\section{References}

1. Gao, Y.; Li, B. Extraction of refined oil from citrus peel by supercritical CO2 fluid. J. Univ. Shanghai Sci. Technol. 2005, 27, 207-210.

2. Angioni, A.; Barra, A.; Coroneo, V.; Dessi, S.; Cabras, P. Chemical composition, seasonal variability, and antifungal activity of Lavandula stoechas L. ssp. stoechas essential oils from stem/leaves and flowers. J. Agric. Food Chem. 2006, 54, 4364-4370. [CrossRef] [PubMed]

3. Bakkali, F.; Averbeck, S.; Averbeck, D.; Idaomar, M. Biological effects of essential oils- A review. Food Chem. Toxicol. 2008, 46, 446-473. [CrossRef] [PubMed]

4. Smith, R.L.; Cohen, S.M.; Doull, J.; Feron, V.J.; Goodman, J.I.; Marnett, L.J.; Portoghese, P.S.; Waddell, W.J.; Wagner, B.M.; Hall, R.L.; et al. A procedure for the safety evaluation of natural flavor complexes used as ingredients in food: Essential oils. Food Chem. Toxicol. 2005, 43, 345-363. [CrossRef] [PubMed]

5. Kiefer, J.; Lampe, A.I.; Nicoli, S.F.; Lucarini, M.; Durazzo, A. Identification of Passion Fruit Oil Adulteration by Chemometric Analysis of FTIR Spectra. Molecules 2019, 24, 3219. [CrossRef] [PubMed]

6. Sarkic, A.; Stappen, I. Essential oils and their single compounds in cosmetics-A critical review. Cosmetics 2018, 5, 11. [CrossRef]

7. Svoboda, K.; Greenaway, R.I. Lemon scented plants. Int. J. Aromather. 2003, 13, 23-32. [CrossRef]

8. Palazzolo, E.; Laudicina, V.A.; Germanà, M.A. Current and potential use of citrus essential oils. Curr. Org. Chem. 2013, 17, 3042-3049. [CrossRef]

9. Azman, N.F.I.N.; Azlan, A.; Khoo, H.E.; Razman, M.R. Antioxidant Properties of Fresh and Frozen Peels of Citrus Species. Curr. Res. Nutr. Food Sci. 2019, 7, 331-339. [CrossRef]

10. Bertuzzi, G.; Tirillini, B.; Angelini, P.; Venanzoni, R. Antioxidative action of citrus limonum essential oil on skin. Eur. J. Med. Plants 2013, 3, 1-9. [CrossRef]

11. Muriel-Galet, V.; Cran, M.J.; Bigger, S.W.; Hernandez-Munoz, P.; Gavara, R. Antioxidant and antimicrobial properties of ethylene vinyl alcohol copolymer films based on the release of oregano essential oil and green tea extract components. J. Food Eng. 2015, 149, 9-16. [CrossRef]

12. Mahato, N.; Sinha, M.; Baral, E.R.; Cho, M.H. Citrus essential oils: Extraction, authentication and application in food preservation. Critic. Rev. Food Sci. Nutr. 2017, 59, 1-16. [CrossRef] [PubMed]

13. Riham, G.R.; Ben, J.M.; Charcosset, C.; Fourmentin, S.; Greige-Gerges, H. Retention of eucalyptol, a natural volatile insecticide, in delivery systems based on hydroxypropyl-ß-cyclodextrin and liposomes. Proteonomics 2020, 122, 1-24.

14. Cortesi, R.; Esposito, E.; Luca, G.; Nastruzzi, C. Production of lipospheres as carriers for bioactive compounds. Biomaterials 2002, 23, 2283-2294. [CrossRef] 
15. Santos, M.C.; Mehner, W.; Schaller, M. Drug targeting by solid lipid nanoparticles for dermal use. J. Drug Targ. 2002, 10, 489-495. [CrossRef]

16. Lippacher, A.; Muller, R.H.; Mader, K. Investigation on the viscoelastic properties of lipid-based colloidal drug carriers. Int. J. Pharm. 2000, 196, 227-230. [CrossRef]

17. Wissing, S.A.; Muller, R.H. The influence of the crystallinity of lipid nanoparticles on their oclusive properties. Int. J. Pharm. 2002, 242, 377-379. [CrossRef]

18. Blake, E. The Microstructure and Physical Properties of Plant-Based Waxes and Their Relationship to the Oil Binding Capacity of Wax Oleogels. Ph.D. Thesis, The University of Guelph, Guelph, ON, Canada, 2015; p. 189.

19. Cabrera, S.; Rojas, J. Oleogels and their contribution in the production of healthier food products: The fats of the future. J. Food Nutr. Res. 2020, 8, 172-182.

20. Chuberre, B.; Araviiskaia, E.; Bieber, T.; Barbaud, A. Mineral oils and waxes in cosmetics: An overview mainly based on the current European regulations and the safety profile of these compounds. J. Eur. Acad. Dermatol. Venereol. 2019, 33, 5-14. [CrossRef]

21. Márquez, R.J.; Molina, V. Technological use of beeswax for obtaining organic products, non-toxic for the human being. Rev. Cien. Ing. 2019, 40,17-26.

22. Martinsa, A.J.; Cerqueira, M.A.; Fasolinc, L.H.; Cunhac, R.; Vicente, A.A. Beeswax organogels: Influence of gelator concentration and oil type in the gelation process. Food Res. Intern. 2016, 84, 170-179. [CrossRef]

23. Jana, S. Crystallization Behavior of Waxes. Ph.D. Thesis, Utah State University, Logan, UT, USA, $2016 ;$ p. 199.

24. Gomes-da Silva, J.Y.; Benjamin, S.R.; Florindo-Guedesa, M.I.; Silva de Freitas, A.; Machado de Sousab, P.H.; Soaresc, D.J. Carnauba wax uses in food-A review. Food Chem. 2019, 291, 38-48.

25. Zhang, Y.; Adams, M.; Zhang, Z.; Vidoni, O.; Leuenberger, B.H.; Achkar, J. Plasticisation of carnauba wax with generally recognised as safe (GRAS) additives. Polymer 2016, 86, 1-33. [CrossRef]

26. Berenice, O. Pectin-candelilla wax: An alternative mixture for edible films. J. Microbiol. Biotechnol. Food Sci. 2015, 5, 167-171.

27. Toro-Vasquez, J. Thermal and textural properties of organogels developed by candelilla wax in satflower oil. J. Am. Oil Chem. Soc. 2007, 84, 989-1000. [CrossRef]

28. Liebert, M.A. Final report on the safety assessment of fossyl and synthetic waxes. J. Am. Coll. Toxicol. 1984, 3, 43-57.

29. Tavernier, I.; Doan, C.D.; de Walle, D.V.; Danthine, S.; Rimaux, T.; Dewettinck, K. Sequential crystallization of high and low melting waxes to improve oil structuring in wax based oleogels. RSC Adv. 2017, 7, 12113-12125. [CrossRef]

30. Cabrera, S.; Rojas, J. Essential oils structuring: A developing strategy to preserve their biological activity and improve their stability. J. Adv. Pharm. Tecnol. Res. Tecnol. Res.. in press.

31. Patel, A.R.; Babaahmadi, M.; Lesaffer, A.; Dewettinck, K. Rheological profiling of organogels prepared at critical gelling concentrations of natural waxes in a triacylglycerol solvent. J. Agric. Food Chem. 2015, 63, 4862-4869. [CrossRef]

32. Doan, C.D.; Van de Walle, D.; Dewettinck, K.; Patel, A.R. Evaluating the oil-gelling properties of natural waxes in rice bran oil: Rheological, thermal, and microstructural study. J. Am. Oil. Chem. Soc. 2015, 92, 801-811. [CrossRef]

33. XIA, Q. Understanding Gelation Systems with Different Gelling Mechanisms in Foods. Ph.D. Thesis, Rutgers The State University of New Jersey, New Brunswick, NJ, USA, 2016; p. 121.

34. Prakash, J.; Jamuna, P.; Jyothi, L.A. Antioxidant properties of fresh and processed Citrus aurantium fruit. Cogent Food Agri. 2016, 2, 1184119.

35. Lopes-Campêlo, L.M.; Moura-Gonçalves, F.C.; Mendes-Feitosa, C.; de Freitas, R.M. Antioxidant activity of Citrus limon essential oil in mouse hippocampus. Pharm. Biol. 2011, 49, 709-715. [CrossRef] [PubMed]

(C) 2020 by the authors. Licensee MDPI, Basel, Switzerland. This article is an open access article distributed under the terms and conditions of the Creative Commons Attribution (CC BY) license (http://creativecommons.org/licenses/by/4.0/). 